International Research Journal of Management, IT \& Social Sciences
Available online at https://sloap.org/journals/index.php/irjmis/
Vol. 7 No. 1, January 2020, pages: 19-30
ISSN: 2395-7492
https://doi.org/10.21744/irjmis.v7n1.817

\title{
The Challenges and Prospects of heritage sites in Ethiopia in case of Tirusina Mosque
}

\begin{abstract}
(1) CrossMark
MuhamedAwal Mehadi ${ }^{\text {a }}$
\end{abstract}

Article history:

Received: 27 November 2019

Accepted: 18 December 2019

Published: 09 January 2020

\section{Keywords:}

heritage potentials; heritage site; heritage values; tourism challenges; tourism development;

\begin{abstract}
In this paper, the researchers will briefly examine the pitfalls of tourism development in the Amhara region taking the Tirusina mosque as a heritage site as a case. Ethiopia is a country with untapped tourism potential. Despite the immense opportunities that exist in Ethiopia in terms of both cultural and natural resources for tourism development, the country continues to lag behind other economies in the region in terms of tourism growth and development. Besides the lack of society's presumption about the important of tourism for the development of the country's economy, no more work was done to improve and increase the flow of tourist arrivals for the reason that our country has strong potential as a tourism destination offering a rich array of cultural, historic and natural sites that set it apart from its neighbors. This helps to investigate and document the tourism sites of the region under study. The researcher will conclude by presenting a series of challenges for those involved in developing the tourism sectors to enhance the development of the country's economic base. Therefore, to understand more about the heritage values of the study area, further identification of the tourism sites and a well-organized work associated with heritage potentials of the site should be conducted on the site to add some information which will be necessary to provide historical significance of the tourism sites of southern part of Wallo zone on one hand and to know the contemporary state of conservation problem of the site on another hand.
\end{abstract}

International research journal of management, IT and social sciences (C) 2020. This is an open access article under the CC BY-NC-ND license (https://creativecommons.org/licenses/by-nc-nd/4.0/).

Corresponding author:

MuhamedAwal Mehadi,

Raya University, Maychew, Ethiopia.

Email address: mumehadi@gmail.com

Raya University, Maychew, Ethiopia 


\section{Introduction}

Heritage sites help to achieve economic development and to alleviate poverty if it is protected, conserved and wellpromoted for the public to gain economic advantage through tourism. It is important to identify potential heritage resource sites and it has to be the prior issues rather than focusing on the utilized destinations. From the potential tourism heritage sites of the Oromo Zone of Amhara region, the Tirusina mosque is one.

The zone has immense natural, cultural, and historical heritage resources that have untapped tourism potentials but these opportunities have been missed for a long period of time. Therefore, this study is to be a turning point to exploit the cultural heritage that is found in the site and how to protect that heritage within the site from further damage to pass on for the next generation.

Among the potential heritage resources of Ethiopia, the Oromo Zone of Amhara region is known by various cultural and natural heritage sites. Although the Zone has tourism potentials because of the availability of many historical, religious, cultural and natural resources, it is not benefited from the tourism sector due to different problems.

Due to this, cultural heritage resources in the Zone were not promoted and positioned. In light of this, there were also different existing problems recognized by the Oromo Zone Culture and Tourism Office related to tourism development in the area. For example, poor infrastructural development, information inaccessibility, less governmental and non-governmental attention, limited cultural heritage professionals, and lack of integrating tourism plan and policy.

The main objective of this study is to assess the importance of the Tirusina mosque as a site of heritage resources. Specific Objectives:

a) To identify the heritage resources in the country yard of Tirusina.

b) To know the existing and potential heritage resources of the mosque.

c) To know and solve the problem that faces heritage treasures found within the site of the study area.

d) To identify the current situation of the Tirusina mosque and other heritage resources found within the same compound.

\section{Materials and Methods}

For the accomplishment of this seminar paper, the researcher used:

a) Written sources such as articles, documents of cultural and tourism bureau of Oromo zone of Amhara region and different pamphlets.

b) Unwritten sources such as interviews as well as fieldwork observation and

c) Different materials such as papers, mobile to capture pictures and record voice, pen and meter.

This study has various significance. The followings were the significance of the study area:

a) It served as a source for developers, designers, and planners of cultural heritage professionals to know the history and architectural style of the mosque and to protect it from further damage.

b) It paves the way for further investigation and research on the problems with the heritage conservation in the site.

c) It brings to light to develop questions and to have basic information about what type of heritage within the site and how to conserve it and pass it to the next generation.

d) It enables us to identify the problems ad come up with the solution after knowing issues hindering the heritage resources and the capability of an area for the creation of new tourism products or services.

The study was focused on the assessment and identification of the heritage resources of the Oromo Zone of Amhara region in particular with the Tirusina mosque. It is recognized that in some ways, any research work would have different limitations. This research had also encountered different major limitations. One of the limitations of this study was that the absence of written documents on the study area especially with the connection to heritage and the values of this heritage for the local community in particular and for all other societies, in general, was not incorporated in available written sources on the site. 
The other limitation of this research was transportation problems that highly encountered the Researcher during field observation and limited documents related to Oromo Zone cultural and tourism resources were the main limitations of the study.

\section{Results and Discussions}

\section{Historical Background of Tirusina Mosque}

The site of the study area is found in the Amhara regional state of the Oromo zone. This name is renamed from the inhabitants of the region whose ethnic background is Oromo and have their own language called Afaan Oromo. The Oromia zone is bordered on the southwest direction by Semien Shewa, on the North West by South Wallo, and Argobba special woreda, and on the east by the Afar region. Kamise is the administrative center of the zone.

This zone has numerous natural, cultural as well as historical tourist attraction sites from the potential heritage resources found in the study area, the most prominent once are: Fulwuha spring water, Chechate, and Berkana spring waters and Rake forest, which are categorized under natural heritage resources while Bati and Sanbate gabeya or market, Tirusina, Shonke, Doddota, Birreensa, Faki, and Mufti mosques are grouped under historical and religious heritage sites respectively (Pamphlet, 2015). Most of the inhabitants of the study area are followers of Islamic religion and most of the heritage sites in the zone are also connected to religion.

\section{The Introduction of Islam in Wallo}

Despite the strong identification of Ethiopia with (Orthodox) Christianity, Islam in Ethiopia is as old as Islam itself. The history of Islam in Ethiopia dates back to 615 A.D when the companions of the Prophet Mohamed (the sahaba) came to Axum fleeing religious persecution by the Quraysh ruling elite in Mecca.

Midst of this persecution the Prophet advised the sahaba to migrate to Axum where they would be protected by a righteous king, widely known in the Arab world as Najashi. Central to Najashi's reputation is his refusal to take a bribe in return for handing over the sahaba to the Quraysh. Appreciative of Najashi's favor, the Prophet is believed to have made the following politically important historic statement in a Hadith regarding Ethiopia: utruku al-habasha ma tarakukum ("Leave the Abyssinians/Ethiopians alone, so long as they leave you alone"). According to Islamic traditions, this is the reason why the early conquest was not extended to Ethiopia at a time when all countries in the Red Sea sub-region succumbed to the new Islamic political and military power. It is also widely believed in the Islamic world and among the Ethiopian Muslims that Najashi not only protected the sahaba but also ultimately embraced Islam (Feyissa \&Lawrence, 2014; Amerta et al., 2018).

Islam gained access to Ethiopia especially through the red sea and gulf of Aden coastal areas which were remote from any direct and effective control of Aksumite state and indirectly through converts from among the nomadic populations of the desert of the horn (Tedessa Tamrat, 1965).

The earliest contact between Islam and the Ethiopian hinterland was forged by traders from the coast and the nomadic element of the interior. The development of trade and the proliferation of commercial routes both along the northern axis of Aksumite domain in the direction of dahlak island and in that part of hinterland facing the eastern littoral in the south and the activities of Muslim traders who were officially tolerated by the Christian state /although not allowed the free exercise of their faith (Tedessa Tamrat, 1965).

Tirmingham wrote "crab traders, artisans, and adventures were the chief medium of Islamic expansions and coming as they did as individuals and not as tribes they naturally lived in close touch with the natives adopted their language instead of imposing Arabic and intermarried with them (Tirmingham, 1965).

The Sultanates of Shoa (9th - 13th century) and Ifat (13th - 15th) were the principal core of Islamic activities during the medieval period in Ethiopia particularly in Northeast Shoa. It was from the sultanate of Ifat in Shoa that Islam gradually spread into the nearby areas and Wello particularly to Dawway and Qallu as well as into the rest of Wello and neighboring provinces (Kassaye Begashaw, 2009).

According to Hussein the introduction of Islam into Wallo was related to trade. Those who received basic qur'anic and advanced instructions had to cope with the considerable economic hardship and the necessity of perpetual traveling in search of specialized teachers. Thus Islamic education in Ethiopia can be said to have frosted trade which

Mehadi, M. (2020). The challenges and prospects of heritage sites in ethiopia in case of tirusina mosque. International Research Journal of Management, IT and Social Sciences, 7(1), 19-30. 
in turn indirectly facilitated the expansion of Islam (Hussein Ahmed, 2001). Islam was brought to the eastern fringes of Wallo from the end of the ninth to the twelve century.

\section{Foundation of the Mosque}

Tirusina Mosque is found along the main road from Addis Ababa to Dessie town after reaching the town of Kamise, which is found on a distance of $325 \mathrm{~km}$ from Addis Ababa towards the northwest direction (Pamphlet, 2016). The village is basically found in Dawa Chaffa district, in a Jille dhumuga kebele, six (6) KM from Shakla town and sixteen (16) KM from Kamise, the capital city of the Oromo zone of Amhara region. The Tirusina Mosque has 80 pillars in outside of the mosque. It is a cone-shaped Mosque.

It took nine years to complete the construction of the whole mosques in the compound. The prayer mosque, which is basically referred to as the male mosque has 8 windows and five doors while the female mosque has only three doors and has no windows. It is $20 \mathrm{~m}$ wide. The male mosque is the biggest mosque in the compound. The inner part of the mosque was decorated by the beautiful and wonderful art of work and has a shape of a star that has six stars encircled by wood. In this compound, there are many houses available separately for both males and females. They are used as dormitory both for males and females one dormitory house has the ability to contain from $4-5$ students each.

In order to construct this religious and historic mosque of Tirusina, the contribution of Sheikh Muhamad Aman was great. He was a great well known Sufi sheik, who was born in a particular place called Dana in Yejju awreja. After he came to Tirusina in 1940, he was the architect of this mosque. The first Imam (Leader) of the mosque was called Sheikh Muhamad Siraj, and he had been many dresses (students) and Kadeem (a person who receives guests and organizes the work within the site).

Around the year 1950, this great leader died while he left many dressed and his followers in this mosque that means both female and male mosques which were constructed when he was alive and the other buildings in the compound were constructed in 1950 after his death by his deresse. During the year 2004, the second wali of the mosque is the second since Terusina's founding and is called sheik Sayyad (Jon Abbink, 2008). The third wali of the mosque died one year ago and he was called Sheikh Abdisamad Jemal and at present time the mosque has no wali

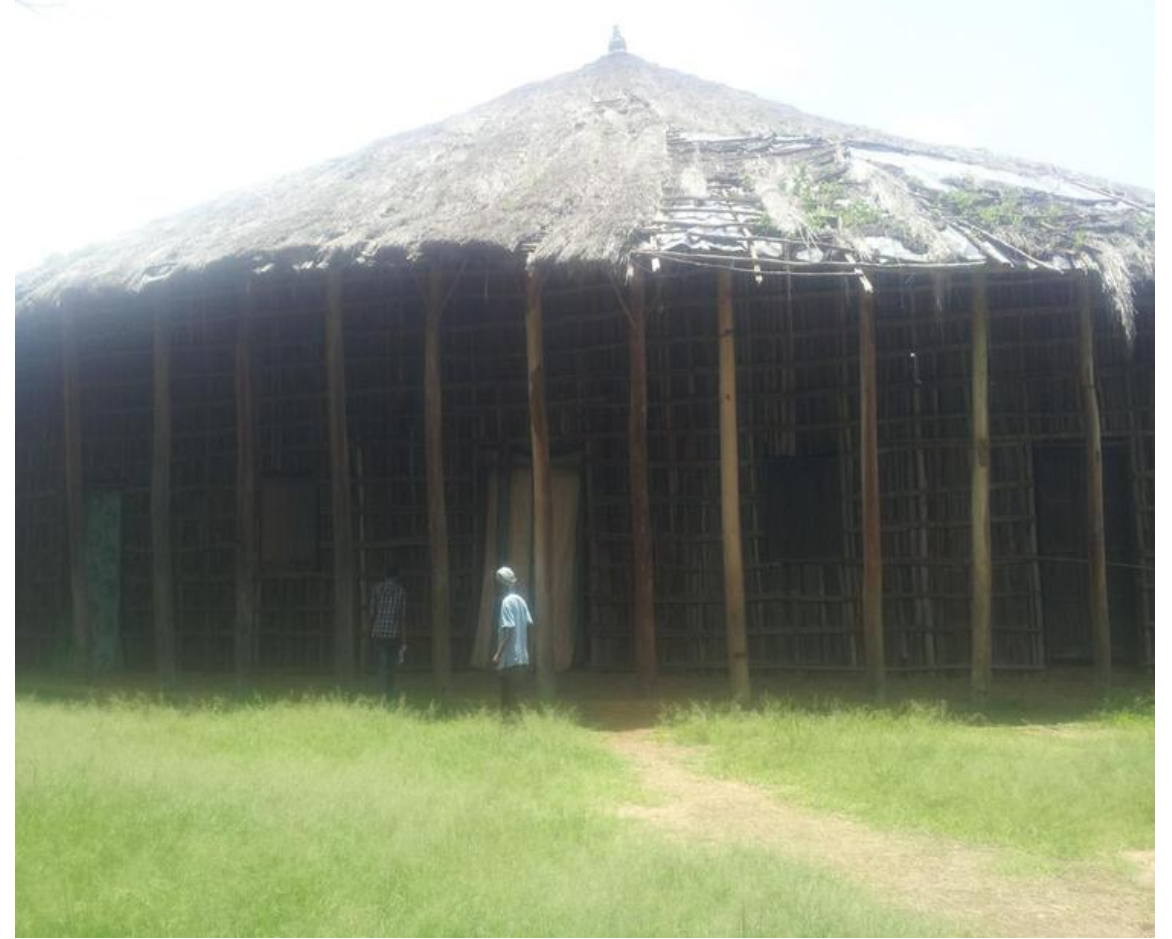

Figure 1. Tirusina mosque, 2016 


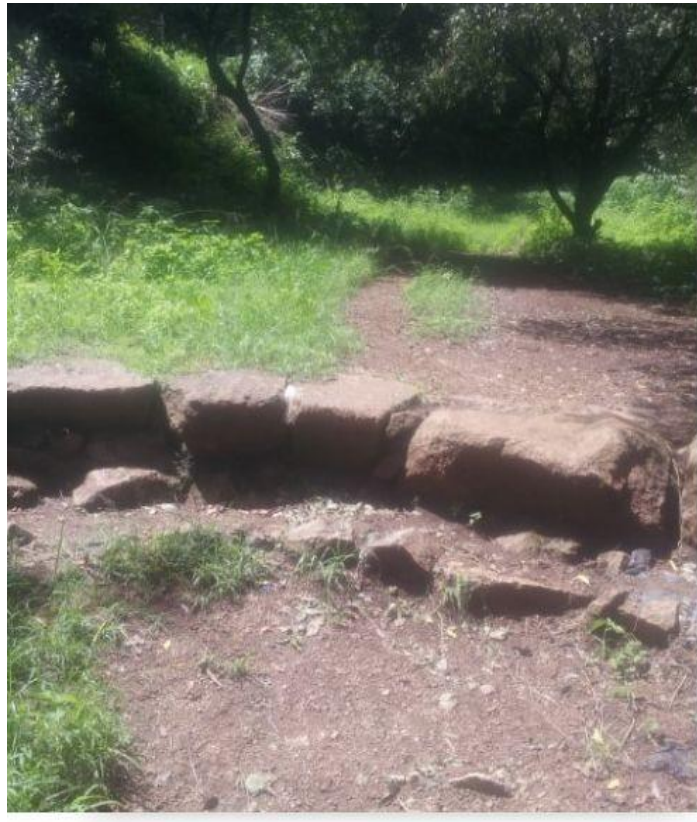

antries of the mosque

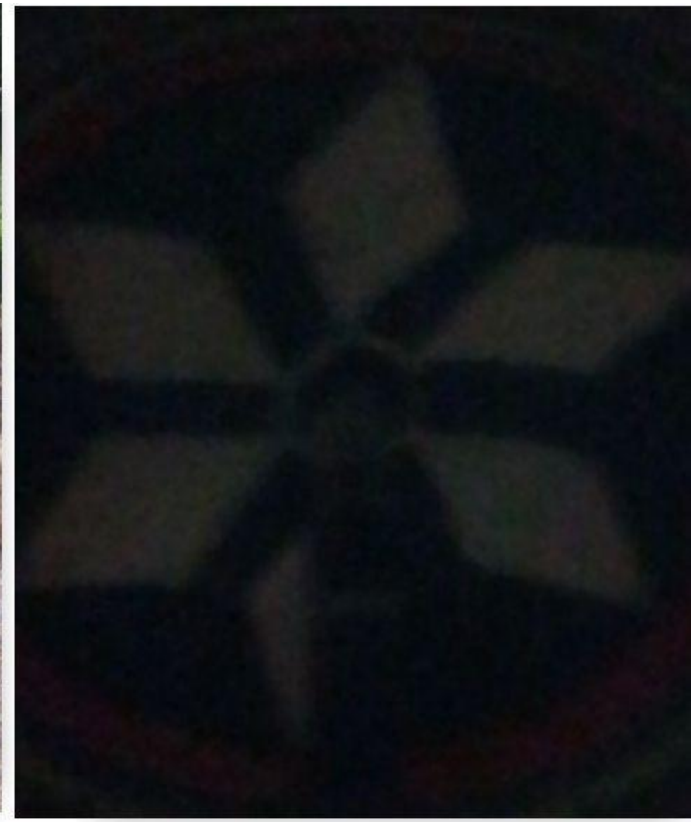

b,the inner part of mosque

Figure 2. The entries of the compound and inner part of the mosque

Starting from its foundation this mosque was used as a center of Islamic learning and many of the deresse (students) were attracted by the site from different regions of Ethiopia as well as even from outside countries such as Somalia, Djibouti, and Eritrea (Zeleke, 2013). During the year 2004, John Abbink said that "The total number of males here is ca.150. The nunnery nearby has about 100 women. While some married men live in the male comp" (Jon Abbink, 2008).

In the current times, the number of the female nunneries was increased to 120, while from these two of them were left the nunnery life and they are 118 female nunneries continued to live the spiritual life nowadays. The male nunnery in the site are 100 deresse, unlike that of female, male nunneries can leave the nunnery life if they want and can also return back based on their choices or personal interest. The perspective of the community towards female and male nunneries is different because females are not encouraged to leave the nunnery life.

In the current time, the types of tourism in the study area are not restricted to the followers of only the religion of Islam but they were from different religious backgrounds as well as ethnic and economic backgrounds. Traditionally us we all know those peoples involved in religious tourism to those important heritage sites are simply called pilgrims but nowadays many non-religious individuals also embark on trips to religious heritage places because many of these sites are of cultural or historical as well as religious interest.

According to my informant, those going to the shrine is called Ziyara. The pilgrims at the site took place twice in a year that is in August and October respectively. Peoples go to the Tirusina heritage site annually for the search of Baraka of the prominent wali or sheik.

During the mawlid and other celebrations, thousands of the participants visit the site and participate in the celebration. The participants at the shrine are from different ethnic, religious and social-economic and political backgrounds and they came to the area with many intentions and gifts like goats, coffee, sheep, and with what their ability allows them and they were able to do so.

\section{Heritages of the Tirusina Mosque}

Heritage is divided into natural and cultural heritage. Tirusina heritage site was endowed both with natural and cultural heritage. Most of the heritage type located within the study area is cultural heritage. The type of cultural heritage here

Mehadi, M. (2020). The challenges and prospects of heritage sites in ethiopia in case of tirusina mosque. International Research Journal of Management, IT and Social Sciences, 7(1), 19-30. 
is distinguished into tangible and intangible cultural heritages as it was known in other places where society shapes their own way of life.

\section{Tangible cultural heritages in Tirusina Mosque}

There are many heritage resources available in Tirusina Mosque. From these the prayer mosque both female and male mosques, Honey house (mar bet) and Guesthouse, Coffee house (Buna bet), Meat house and those materials used in each house to prepare food and beverages. They are amazingly seen by tourists because they were made from woods, clay and other traditional materials which are rare and even not found in other places.

\section{Honey historical house}

It is also called a guest house because if the guest goes to that site they were received to this house. Honey was collected from inhabitants of the area and some of it was brought from the neighboring towns such as Kamise, Dessie, and Shewa Robit and even by going as far distance from the site to Addis Ababa. In this house, there were various materials gathered from the inhabitants of the area and some of them brought and others made from the local woods and exists today in the house. They had been used for enormous purposes like to change the honey from one container to the other, to avail the honey to the customers, and also to use the honey from it.

There is also a small hut of a house constructed between mosque and honey house for the purposes of storing honey. It's temporal storage which is not more than one year .this is because to avail honey to the attendees participated in the mawlid and wadaja ceremony. The following are heritage materials found in this house.
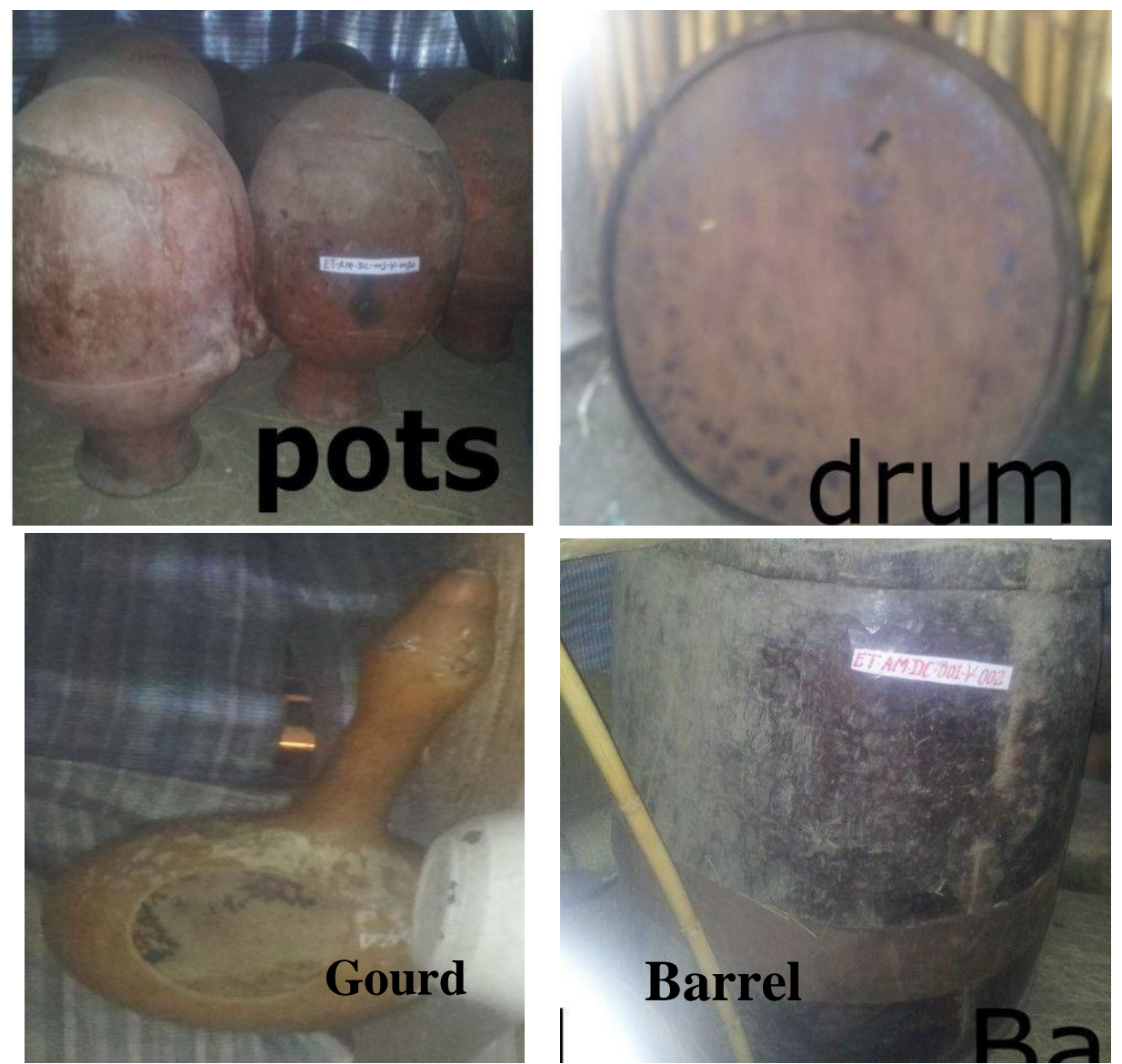

Figure 3. Treasures in a honey historical house 


\section{Meat House}

Meat house is a place when you found the materials used to hold, cut, and prepare meat. They are more than forty materials available for this job. They are more than ten traditional mortars in this historical house which was made from a single wood.

They are two four meters long with a width of one meter. They were used for many functions such as to cool the meat, to avail it to the user, to hold raw meat and to eat from it.

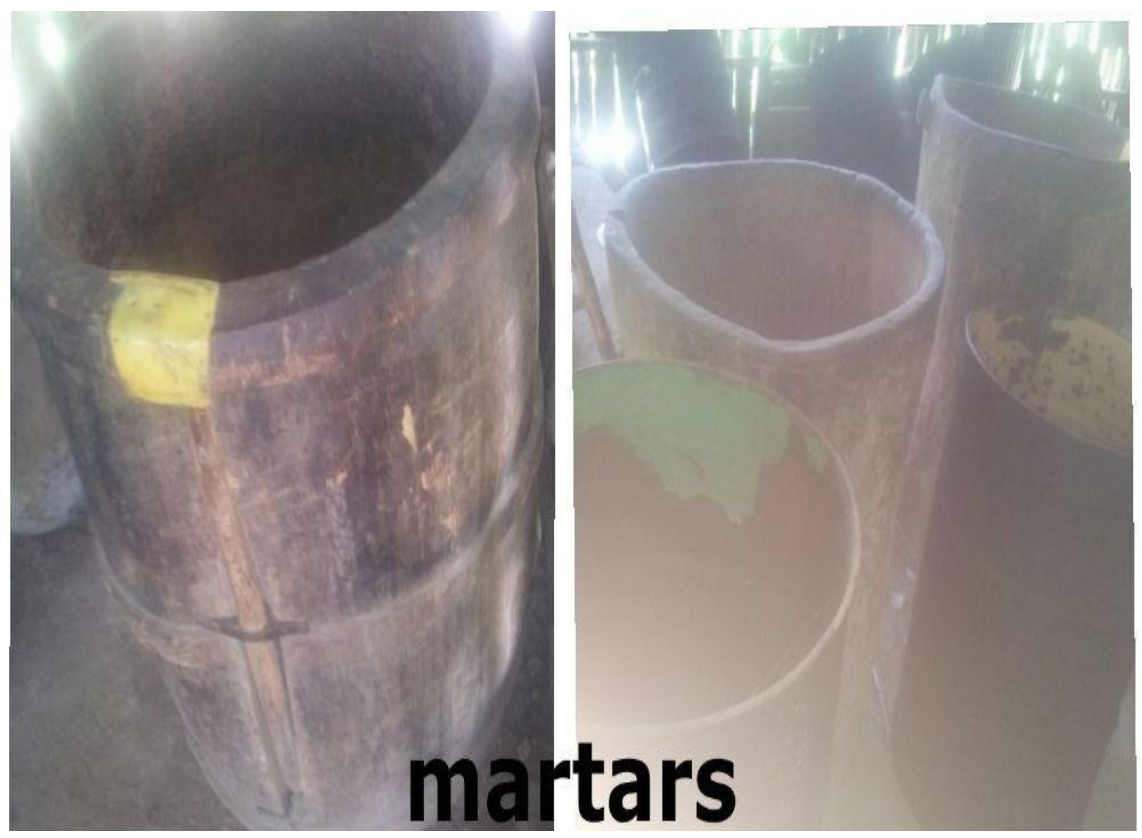

Figure 4. Heritage materials in the meat house

\section{Coffee House}

It is a place where coffee is gathered by the community of the area and also collected from those who need the Baraka of the sheikh and come up with it during the time of mawlid (the birthday of prophet Muhamad) and other celebration in the mosque. Enormous materials are found in this storehouse.

The function of all of these houses in the compound is not the same. In the coffee house, the only materials available are cups, jabenas, makocha (mortar), which are used for the preparation of coffee.

a) Cups, There are more than 1000 cups of coffee in this house. The numbers of cups are sometimes not equivalent to that of the number of people who attendees the mawlid celebration.

b) Kettle, There are 31 coffee pots in numbers. From these coffee pots, two of them are odd because they have two holes which are used to drop coffee at a time. They are called v-shaped kettles which are used to drop coffee into two cups within time because this is important and used widely depending on the number of attendees of the mawlid and it is used to save time.

c) Rokobot, it is made of wood and has a rectangular shape. There are two rokobots (cup holders) in the site which vary in the size and the number of cups holds at a time. The largest one which has two-meter length and one-meter wide has a capacity to contain more than five hundred cups at a time while the smallest, which has only one meter up to five-centimeter length and $50 \mathrm{~cm}$ width has a capacity to hold more than one hundred forty cups.

d) Gulicha (trivet), traditionally trivet is something which used is by most of the societies by providing it from materials available and near to their site. Some of them were made of clay and stones. It is used especially during the time of food preparation to put the materials used to prepare food on the fire. Initially, the type of trivet used in the Tirusina heritage site was made from stones but later it was replaced by clay.

e) Cilfa (dipper), is also the other materials which were used widely to transfer water from one container to the

Mehadi, M. (2020). The challenges and prospects of heritage sites in ethiopia in case of tirusina mosque. International Research Journal of Management, IT and Social Sciences, 7(1), 19-30. https://doi.org/10.21744/irjmis.v7n1.817 
other. It is a cup-shaped vessel with a long handle used for dipping out liquids.

f) Mortar, it is a hollow vessel that is used to pound, crush, rub, grid, or mix ingredients with a pestle. There are four mortals. It is the smallest one that is traditionally used in the home to crush coffee but it the biggest one which was used to crush wheat, barley, and maize. All of them have a capacity to contain one quna, traditional materials which are used to measure solid things like wheat, barley and etc.

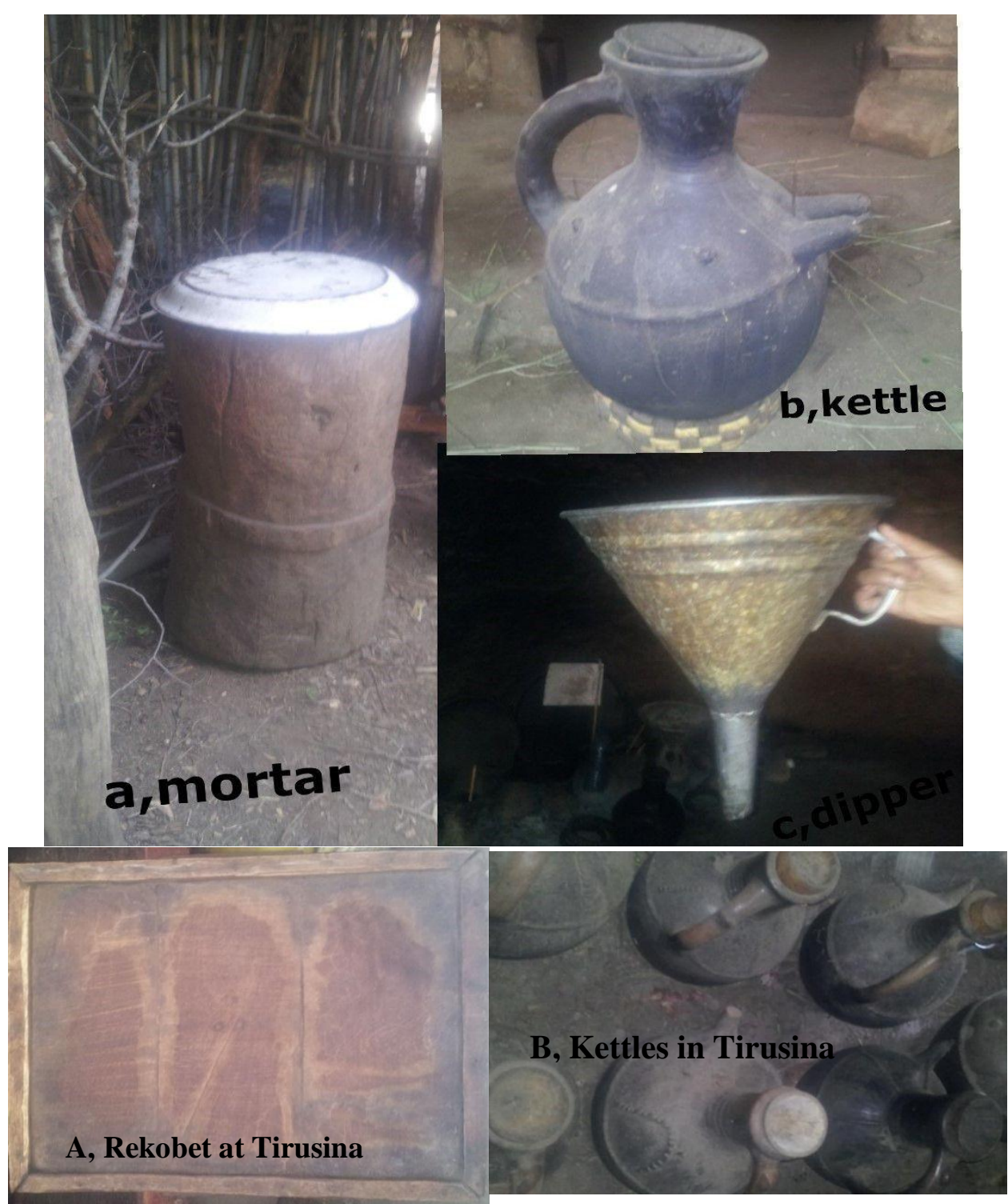

Figure 5. Heritage treasures in a coffee house

The significance Tirusina heritage site

The mosque of Tirusina has importance for religious and architectural values to the local community as well as to all communities interested in it.

a) Religiously it is believed as a place where people of different ethnic and socio-economic backgrounds gathered together as pilgrims which are commonly called ziyara, a visit to the site.

b) Economically, the mosque is used as a source of income because when the people visit the site they had given different gifts for the mosque and the particular wali of the site which is important to boost their economy. 
In addition to the economic benefits, the heritage site of the study area served as a source of tourism which plays a significant role in the socio-cultural developments of both visitors and the local inhabitants.

a) Experiencing different cultural practices increase insight and appreciation for different approaches to living. By learning more about others, the difference among people of various ethnic groups becomes less threatening and more interesting.

b) Moreover, the interest of tourists in local culture and history provides an opportunity to support the preservation of historical artifacts, and the coming of tourists to the destinations leads to the betterment of social services and social utilities, which is enjoyed by the local population.

c) It has also architectural values, the way and how this very great mosque was constructed from wood was amazing. In it is inside the mosque has forty-one pillars while there are eighth five pillars from outside. In order to refresh their minds peoples visited the site.

Generally, the specific benefits that a community can accrue through tourism are largely related to the increment of the living conditions of the community and economic growth by creating job opportunities.

\section{The current condition of tirusina heritage site}

Nowadays the site of the study area needs some repair especially on the top of its roof of the mosque. This the beautiful architectural style of the mosque loses it is originality and even when the rain falls it enters the water into the inner part of the mosque. There are no experts found at the site for the prevention, consolidation, and restoration of the mosque from damage before and after it happens. The same is also true for treasures found on the site.

The absence of the museum to collect and organize these precious materials in the compounds is also one of the obstacles facing this important heritage site. The traditional effort used in the site for a long period of time by collecting various materials based on their function in different houses such as a honey house, coffee house, and meat house was not enough for the preservation and protection of those materials from risk because their organizations were not supported by scientific method.

They were also not free from problems of rat, sunlight, air, and movements from place to place by everyone without an expert or professionals. Everyone can touch, move and put the heritage treasures in Tirusina heritage destination at a place he/she interested in after visiting the object.

In addition to this since the mosques and buildings in the compounds were constructed from wood and grass, if a fire happened in the destination it is very hard to stop it from destruction because the geographical location of the site itself is suitable for that and also the buildings are near to each other. In recent days most of the traditional materials such as Barrels, Kettles, and Trivet were replaced by the modern one.

\section{Challenges and opportunities of conservation in case tirusina}

\section{Problems}

There are many problems that face the heritage conservation of the study area but the main important constraints are the shortage of skilled manpower, lack of heritage guide and conservation professional, lack of knowledge about the value of the site, absence of museum for the collection of this precious heritage, lack of accommodation, accessibility, absence of written documents, lack of documentation and well-planned documentation and etc.

\section{Lack of documentation and well-organized information}

In order to protect the history of the site and promote this historical, cultural and religious heritage site the effort of individuals, groups and even the experts of cultural and tourism bureau of Oromo zone of Amhara regional state is not as such strong because it is difficult to find information that well documented on all heritage treasures exists within the Tirusina heritage site.

As already tried to explain earlier in order to conserve, preserve, reconstruct and promote the heritage resources of Tirusina heritage place there should be a trained personal and has well experienced on a field of heritage and has sufficient information about the site.

Mehadi, M. (2020). The challenges and prospects of heritage sites in ethiopia in case of tirusina mosque. International Research Journal of Management, IT and Social Sciences, 7(1), 19-30. 


\section{Advertisement problem}

The other area of poor performance in the activities of the heritage conservation in the site is the promotion aspect. Advertisement is one of the most important ways in which many peoples know about the potential resources of a particular heritage site and helps to encourage the economy by allowing the visitors who were interested to tour the site. Advertisement of the countries resource tourist attraction site helps to create awareness and increase the inflow of tourists. Without advertisement historic area unknown to the potential tourists of the world as a whole (Yohannes Bekele (2001).

In this regard, it is very difficult to say the Tirusina Mosque, which has both historic and cultural importance both for the countries in general and the surrounding communities, in particular, is well advertised both at national as well as regional levels. Without advertisement of the site by using Medias such as radio, television, newspaper, pamphlets and the like it is difficult to gain a large number of tourists which enables for the increment of the economy of the mosque as well as the inhabitants of the area. In these concerns, some attempts were made by the federal tourism and cultural bureaus which had been seen the site twice in 2013 and 2015 respectively. During this time they prepared pamphlets about the site and distributed for the local communities and those tourists available there at that particular time and put the left in the mosque and cultural and tourism bureau of the Oromo zone of Amhara region.

This is a good beginning to advertise the site but it has also its own limitation because the pamphlet was written only by the Amharic language while the inhabitants of the site are the speakers of Oromic language and many of the tourists are from different ethnic backgrounds, it is necessary to prepare documents written by English.

\section{Shortage of infrastructural services}

The most important and widely known problem that faces the country in general and Tirusina heritage site, in particular, was the lack of infrastructures such as road, electricity, and networking which threat the local community from participating in different alternative activities to minimize the impact on the site. This also affects the flow of a large number of tourists. This important heritage site can be reached by road, either in private vehicle, bajaj or by public buses only during the time of the dry season it is difficult to go to even by foot. If this is solved tourists can reach easily the important heritage site from both domestic and foreign countries.

The quality of transportation is the determinate factor for the accessibility of heritage sites which played a great role in the economic growth of one country by serving as tourist attraction areas. To this fact, because of the lack of modern transportation services, a tourist site in the South Wallo region of the Oromo zone including that of Shonke, Dodota, and Mufti mosques in general and Tirusina Mosque, in particular, had remained unknown to the visitors. The current road from Shakla town to Tirusina Mosque is a recent phenomenon but it has no quality and it lacks standard and is not give safe services as it is expected from the tourist's point of view.

\section{The impact of Man-made and Natural factors on the site}

The site had affected by many problems that are responsible for the reduction of the quality as well as also have a great deal on the physical appearance of the mosque and heritage resources in the site. These problems are grouped under natural and man-made factors which played a significant role in the deterioration of cultural heritage.

The natural factors include rainfall, wind pressure, sunlight and variations of temperatures. Human-made factors such as fire, mass tourism to the site which leads to overpopulation and the destruction of plants within the site.

\section{Opportunities}

Tirusina heritage site is important for the attraction of tourists from different areas because of its potential historical, religious and cultural values. The tourism sector is one essential component of Ethiopia's national development and transformation. It is set in a national environment that faces tremendous opportunities such as:

a) The income the Tirusina heritage site generates from those tourists visit the site was used to conserve and protect the heritage treasures and the mosques from further damage and used to repair those that were already damaged.

b) It is important for the fast rate of economic growth, a significant expansion of transportation and communication facilities, a massive construction boom and an entrepreneur population.

c) At the same time challenges of widespread poverty, massive unemployment, recurrent food insecurity, and 
underdevelopment of the productive forces of the economy are solved through time to time because of the value the community endowed from this heritage site.

d) Through the conservation of the Tirusina heritage site, the community of the area can also benefit from Tourism, as a labor-intensive sector of the economy which has the potential of improving the lives of people and the economies of communities of different social and economic backgrounds.

\section{Conclusion}

Tirusina heritage site is one of the most important sites found in the Oromo zone of Amhara regional state which has religious, cultural, historical and architectural values. This mosque was built around the year 1940s by a prominent and well-known architect of the time Muhamad Aman who was from Yejju.

I argue that the presence of Muslim monasteries was a new phenomenon that is not found in any other place within the exception of the Tirusina mosque heritage site. In this site females and males are still living in a separate place within the compounds and live only their religious life.

The mosque in particular and the heritage treasures found in the compound, in general, is at present time on the way of destruction, damage, and some of them were damaged and needs repair and maintenance. In order to protect, conserve, repair the heritage management professionals must be tasked with the site for conservation as their main goals which are often at odds with financial, educational and participatory goals which the Tirusina heritage site lacks and still rely on the traditional way of conservation.

\section{Recommendation}

The researcher drew the following recommendation on how to conserve and transfer the Tirusina heritage site from one generation to the other:

a) The heritage visitors should respect the local culture and not damage the heritage treasures and protect the site from dust.

b) The heritage and tourism professionals should work together for the digitization of heritage for the protection and preservation of the site.

c) The cultural and tourism office and the local community should incorporate together to create an archive for the treasures of the Tirusina heritage site.

d) Students, teachers, and every learned person must have to create an awareness of the importance of preserving the site by sharing news and history of the site through social media such as Facebook, radio and etc.

e) The government and NGOs should have to participate in the fulfillment of infrastructures and repairing different treasures and the roof of the mosque from further damage.

f) The cultural and tourism office should incorporate with heritage professionals to give awareness for the society because a lack of knowledge about cultural heritage values is one of the most significant threats to the conservation of these values.

\section{Conflict of interest statement}

The author declared that he has no competing interests.

Statement of authorship

The author has a responsibility for the conception and design of the study. The author has approved the final article.

Acknowledgments

The authors would like to thank the editor of IRJMIS for their valuable time, support and advice in completing the current study.

Mehadi, M. (2020). The challenges and prospects of heritage sites in ethiopia in case of tirusina mosque. International Research Journal of Management, IT and Social Sciences, 7(1), 19-30. https://doi.org/10.21744/irjmis.v7n1.817 


\section{References}

Abbink, G. J. (2008). Muslim monasteries? Some aspects of religious culture in Northern Ethiopia. Aethiopica, 11, 17.

Ahmed, H. (2001). Islam in nineteenth-century Wallo, Ethiopia: revival, reform and reaction (Vol. 74). Brill.

Amerta, I. M. S., Sara, I. M., \& Bagiada, K. (2018). Sustainable tourism development. International Research Journal of Management, IT and Social Sciences, 5(2), 248-254.

Feyissa, D., \& Lawrence, B. B. (2014). Muslims Renegotiating Marginality in Contemporary E thiopia. The Muslim World, 104(3), 281-305. https://doi.org/10.1111/muwo.12056

Kassaye, B. (2009). The Archeology of Islam in North East Shoa. In Proceedings of the 16th International Conference of Ethiopian Studies (pp. 11-22).

Pamphlet (2015). National Cultural and Tourism Office, Tourism resources in Oromo Zone of Amhara Regional state.

Pamphlet (2016). Amhara National Regional State Cultural Tourism and Information Bureau, "Visit the Tourism Resources of Oromo zone Administration".

Tamrat, T. (1966). The Chronicle of'Amde-Sīyon-The Glorious Victories of 'Amde-Șiyon, King of Ethiopia. Translated and Edited by GWB Huntingford. Oxford: Clarendon Press, 1965. Pp. 142, maps, illustrations. 38s. The Journal of African History, 7(3), 511-514. https://doi.org/10.1017/S0021853700006575

Trimingham, J. S. (1965). Islam in Ethiopia. New York: Barnes and Noble.

Yohannes Bekele. (2001). "Basics of Tourism Development”, Tourism manual, Bahirdar, Ethiopia.

Zeleke, M. (2013). The Gendering Discourse in the Debates of Religious Orthodoxy. In Muslim Ethiopia (pp. 115137). Palgrave Macmillan, New York. https://doi.org/10.1057/9781137322098_6 